\title{
Rapid Growth and Childhood Obesity Are Strongly Associated with LysoPC(14:0)
}

\author{
Peter Rzehak ${ }^{a} \quad$ Christian Hellmuth $^{a}$ Olaf Uhla Franca F. Kirchberg ${ }^{a}$ \\ Wolfgang Peissner $^{a} \quad$ Ulrike Harder ${ }^{a}$ Veit Grote ${ }^{a}$ Martina Weber ${ }^{a}$ \\ Annick Xhonneux ${ }^{b}$ Jean-Paul Langhendries ${ }^{b}$ Natalia Ferre ${ }^{c}$ \\ Ricardo Closa-Monasterolo ${ }^{c}$ Elvira Verducid ${ }^{d}$ Enrica Riva ${ }^{d}$ Piotr Socha ${ }^{e}$ \\ Dariusz Gruszfeld ${ }^{\mathrm{e}}$ Berthold Koletzko ${ }^{\text {a }}$ for the European Childhood Obesity \\ Trial Study Group \\ a Division of Metabolic and Nutritional Medicine, Dr. von Hauner Children's Hospital, Ludwig Maximilian \\ University of Munich, Munich, Germany; ${ }^{b} \mathrm{CHC}$ St. Vincent, Liège-Rocourt, Belgium; ' Universitat Rovira i Virgili,

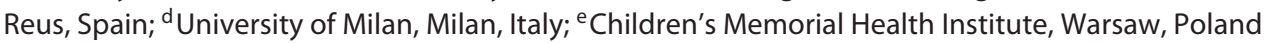

\section{Key Words}

Targeted metabolomics approach · Amino acid and lipid metabolism · Metabolic programming · Infant weight gain · Rapid growth · Childhood obesity

\footnotetext{
Abstract

Background: Despite the growing interest in the early-origins-of-later-disease hypothesis, little is known about the metabolic underpinnings linking infant weight gain and childhood obesity. Objective: To discover biomarkers reflective of weight change in the first 6 months and overweight/ obesity at age 6 years via a targeted metabolomics approach. Design: This analysis comprised 726 infants from a European multicenter randomized trial (Childhood Obesity Programme, (HOP) for whom plasma blood samples at age 6 months and anthropometric data up to the age of 6 years were available. 'Rapid growth' was defined as a positive difference in weight
}

within the first 6 months of life standardized to WHO growth standards. Weight change was regressed on each of 168 metabolites (acylcarnitines, lysophosphatidylcholines, sphingomyelins, and amino acids). Metabolites significant after Bonferroni's correction were tested as predictors of later overweight/obesity. Results: Among the overall 19 significant metabolites, 4 were associated with rapid growth and 15 were associated with a less-than-ideal weight change. After adjusting for feeding group, only the lysophosphatidylcholine $L P C a C 14: 0$ remained significantly associated with rapid weight gain ( $\beta=0.18$ ). Only LPCaC14:0 at age 6 months was predictive of overweight/obesity at age 6 years (OR 1.33; $95 \%$ CI 1.04-1.69). Conclusion: LPCa14:0 is strongly related to rapid growth in infancy and childhood overweight/obesity. This suggests that LPCaC14:0 levels may represent a metabolically programmed effect of infant weight gain on the later obesity risk. However, these results require confirmation by independent cohorts.

\section{KARGER}

E-Mail karger@karger.com www.karger.com/anm
(C) 2014 S. Karger AG, Basel

0250-6807/14/0644-0294\$39.50/0
Prof. Berthold Koletzko

Division of Metabolic and Nutritional Medicine

Dr. von Hauner Children's Hospital, Ludwig Maximilian University of Munich

Lindwurmstrasse 4, DE-80337 Munich (Germany)

E-Mail office.koletzko@med.uni-muenchen 


\section{Introduction}

Early rapid growth has been well established as a risk factor for later obesity since the salient paper of Ong et al. [1] on catch-up growth made this hypothesis a prominent issue [2]. It has been proposed that adverse programming of the metabolic profile by early nutrition in postnatal life may be behind these associations [3]. A recent review emphasized the role of the first 6 months of life in adverse programming of the metabolic profile in infants as the main biological underpinning of such a link [4]. In essence, this review concludes that the biological mechanisms linking infant weight gain to child obesity via metabolic programming are due to metabolic characteristics of the given human or formula milk affecting the metabolic, immunological, and anthropometric response of the infant. Although this review is very informative, it documents that, in contrast to the literature on adults [5, 6], the power of metabolomics still needs to be fully utilized in pediatrics beyond clinical settings in neonatology $[7,8]$. Metabolomics has a great potential for the discovery of biomarkers reflective of weight gain and obesity via examination of alterations in amino acid and lipid metabolism [5-8].

A few studies have applied a targeted metabolomics approach for the analysis of obesity or weight change in child or adolescent populations [9-12]. These publications have mainly been based on small case-control studies of obese and normal-weight children, with a maximum of 160 participants in late childhood or adolescence from clinical settings or even very special populations like anorexic patients [9]. The metabolic profile of weight change has therefore only been assessed in the context of obesity or anorexia treatment, resulting in the analysis of weight loss [12] and weight regain [9], and not in unselected populations. Thus, the metabolic profile of anorexic patients with a mean age of about 15 years [9] is quite different and comprises more metabolites from more species than those found in studies on obese versus normal-weight children and adolescents with an age range of $6-16$ years $[11,12]$.

In obese adults, elevated ratios of amino acids to corresponding short-chain acylcarnitines were reported by Newgard et al. [13]. However, a US study could not confirm these findings in obese or diabetic youth [10] and rejected the hypothesis of impaired fatty acid or amino acid metabolism as a driving force of obesity in youth. Instead, the hypothesis of a 'failure of mitochondrial adaptive mechanisms' in obesity and diabetes is proposed for both adults and adolescents. According to those au-

Metabolites, Early Rapid Growth, and Childhood Obesity thors, difficulties showing this general mechanism in the obese adolescents in that study contributed to a lack of duration of obesity or diabetes. However, that study was based only on 39 normal-weight, 64 obese, and 17 adolescent subjects with type 2 diabetes [10].

Despite the above-mentioned evidence of the importance of the first 6 months of life for programming of the metabolic profile, weight development, and obesity risk of a child, no large unselected population-based study following a comprehensive targeted metabolomics approach has been published so far for this age group. The European Childhood Obesity Programme (CHOP) study, a randomized prospective nutritional intervention study following formula-fed infants with a high or low protein intake, is well suited to investigating the metabolic profile in relation to weight change in infants and older children [14-17]. Moreover, using WHO growth standards [18], a more-than-ideal weight gain ('rapid growth') as well as a less-than-ideal weight gain can be assessed and related to the infant's metabolic markers. In addition, this study comprises an ongoing birth cohort and enables evaluation of the predictive effect of metabolic markers for development of overweight and obesity at the age of 6 years in a genuine longitudinal study. Thus, this study may contribute to reducing the 'causal dilemma' of metabolomics analysis regarding the cause and effect of changes in growth and changes in metabolites.

The aims of this study are therefore: (1) to investigate whether changes in weight in the first 6 months of life are related to levels of amino acids or lipid metabolites using a comprehensive targeted metabolomics approach, and (2) to assess which of these metabolites are also associated with obesity in later childhood at age 6 years.

Answers to such questions may give further insight into the biological underpinnings of the 'accelerated postnatal growth hypothesis' - in particular with respect to the role of metabolic programming of growth and later obesity [3].

\section{Material and Methods}

\section{Subjects and Procedures}

This analysis is based on a subsample of 726 of the 1,678 infants recruited in the first 8 weeks of life for the European CHOP study for whom plasma blood samples for metabolic profiling at the age of 6 months and anthropometric data at birth and 6 months were available. Among these, 394 children also had anthropometric data at the age of 6 years. The CHOP study is an ongoing randomized nutritional intervention trial and birth cohort of formula-fed infants randomized to a high- or low-protein content formula and breast-fed infants in 5 European countries (Belgium, Germany, 
Table 1. Characteristics of the analyzed population

\begin{tabular}{|c|c|c|c|c|c|c|c|c|c|c|c|c|}
\hline & \multicolumn{3}{|c|}{$\begin{array}{l}\text { Low-protein formula } \\
(\mathrm{n}=275)\end{array}$} & \multicolumn{3}{|c|}{$\begin{array}{l}\text { High-protein formula } \\
(n=277)\end{array}$} & \multicolumn{3}{|c|}{ Breast-fed $(\mathrm{n}=174)$} & \multicolumn{3}{|c|}{ Total $(\mathrm{n}=726)$} \\
\hline & $\begin{array}{l}\mathrm{n} \text { or } \\
\mathrm{n} / \mathrm{N}\end{array}$ & $\begin{array}{l}\text { mean } \\
\text { or } \%\end{array}$ & $\begin{array}{l}\text { SD or } \\
95 \% \mathrm{CI}\end{array}$ & $\begin{array}{l}\mathrm{n} \text { or } \\
\mathrm{n} / \mathrm{N}\end{array}$ & $\begin{array}{l}\text { mean } \\
\text { or } \%\end{array}$ & $\begin{array}{l}\text { SD or } \\
95 \% \mathrm{CI}\end{array}$ & $\begin{array}{l}\mathrm{n} \text { or } \\
\mathrm{n} / \mathrm{N}\end{array}$ & $\begin{array}{l}\text { mean } \\
\text { or } \%\end{array}$ & $\begin{array}{l}\text { SD or } \\
95 \% \mathrm{CI}\end{array}$ & $\begin{array}{l}\mathrm{n} \text { or } \\
\mathrm{n} / \mathrm{N}\end{array}$ & $\begin{array}{l}\text { mean } \\
\text { or } \%\end{array}$ & $\begin{array}{l}\text { SD or } \\
95 \% \mathrm{CI}\end{array}$ \\
\hline \multicolumn{13}{|l|}{ Birth weight (g) } \\
\hline Girls & 141 & 3,226 & 321 & 138 & 3,226 & 345 & 98 & 3,299 & 332 & 377 & 3,245 & 333 \\
\hline Boys & 134 & 3,337 & 328 & 139 & 3,336 & 349 & 76 & 3,432 & 408 & 349 & 3,357 & 356 \\
\hline Mothers & 203 & 3,280 & 595 & 208 & 3,281 & 599 & 150 & 3,237 & 597 & 561 & 3,269 & 596 \\
\hline Fathers & 178 & 3,396 & 620 & 180 & 3,566 & 624 & 130 & 3,487 & 567 & 488 & 3,483 & 611 \\
\hline \multicolumn{13}{|l|}{ Birth length $(\mathrm{cm})$} \\
\hline Girls & 141 & 50.5 & 2.8 & 138 & 50.3 & 2.6 & 98 & 50.8 & 2.5 & 377 & 50.5 & 2.6 \\
\hline Boys & 133 & 51.2 & 2.8 & 139 & 51.3 & 3.0 & 76 & 51.9 & 3.2 & 348 & 51.4 & 3.0 \\
\hline \multicolumn{13}{|l|}{ Prepregnancy BMI } \\
\hline Mothers & 271 & 23.7 & 4.5 & 273 & 23.9 & 4.8 & 171 & 22.5 & 3.7 & 715 & 23.5 & 4.5 \\
\hline Fathers & 263 & 26.2 & 3.8 & 267 & 26.1 & 3.7 & 170 & 25.9 & 3.4 & 700 & 26.1 & 3.7 \\
\hline Gestational age (weeks) & 275 & 39.8 & 1.1 & 277 & 39.9 & 1.2 & 173 & 40.0 & 1.2 & 725 & 39.9 & 1.2 \\
\hline \multicolumn{13}{|l|}{ Any maternal smoking } \\
\hline during pregnancy & $132 / 274$ & $48.2 \%$ & $42.2-54.1$ & $117 / 276$ & $42.4 \%$ & $36.5-48.3$ & $26 / 174$ & $14.9 \%$ & $9.6-20.3$ & $275 / 724$ & $38.0 \%$ & $34.4-41.5$ \\
\hline \multicolumn{13}{|l|}{ Parental education } \\
\hline Low & $66 / 275$ & $24.0 \%$ & $18.9-29.1$ & $57 / 277$ & $20.6 \%$ & $15.8-25.4$ & $8 / 174$ & $4.6 \%$ & $1.5-7.7$ & $131 / 726$ & $18.0 \%$ & $15.2-20.8$ \\
\hline Medium & $148 / 275$ & $53.8 \%$ & $47.9-59.7$ & $156 / 277$ & $56.3 \%$ & $50.4-62.2$ & $46 / 174$ & $26.4 \%$ & $19.8-33.1$ & $350 / 726$ & $48.2 \%$ & $44.6-51.9$ \\
\hline High & $61 / 275$ & $22.2 \%$ & $17.2-27.1$ & $64 / 277$ & $23.1 \%$ & $18.1-28.1$ & $120 / 174$ & $69.0 \%$ & $62.0-75.9$ & $245 / 726$ & $33.7 \%$ & $30.3-37.2$ \\
\hline \multicolumn{13}{|l|}{ Country } \\
\hline Germany & $57 / 275$ & $20.7 \%$ & $15.9-25.5$ & $62 / 277$ & $22.4 \%$ & $17.4-27.3$ & $48 / 174$ & $27.6 \%$ & $20.9-34.3$ & $167 / 726$ & $23.0 \%$ & $19.9-26.1$ \\
\hline Belgium & $35 / 275$ & $12.7 \%$ & $8.8-16.7$ & $32 / 277$ & $11.6 \%$ & $7.8-15.3$ & $34 / 174$ & $19.5 \%$ & $13.6-25.5$ & $101 / 726$ & $13.9 \%$ & $11.4-16.4$ \\
\hline Poland & $76 / 275$ & $27.6 \%$ & $22.3-33.0$ & $77 / 277$ & $27.8 \%$ & $22.5-33.1$ & $44 / 174$ & $25.3 \%$ & $18.8-31.8$ & $197 / 726$ & $27.1 \%$ & $23.9-30.4$ \\
\hline Spain & $107 / 275$ & $38.9 \%$ & $33.1-44.7$ & $106 / 277$ & $38.3 \%$ & $32.5-44.0$ & $48 / 174$ & $27.6 \%$ & $20.9-34.3$ & $261 / 726$ & $36.0 \%$ & $32.5-39.4$ \\
\hline
\end{tabular}

Italy, Poland, and Spain). Details of the CHOP study design and procedures have been published previously [14-17]. The study followed the recommendations made in the CONSORT statement [19] and was approved by the ethics committees of all participating study centers, and written informed parental consent was obtained for each infant.

\section{Measurement of Metabolites}

For 764 infants aged 6 months, plasma samples were drawn for metabolite analyses in all study centers (except the center in Milan, Italy, which had not received ethical approval for blood sampling). Parents were asked not to feed their infants for at least $2 \mathrm{~h}$ before the blood draw. Drawn plasma samples were stored at $-80^{\circ} \mathrm{C}$, except at the study center in Belgium, where samples were stored at $-20^{\circ} \mathrm{C}$. Measurements were performed at the Munich laboratory (Division of Metabolic and Nutritional Medicine, Dr. von Hauner Children's Hospital).

Analyses were performed to quantify 168 known lipid metabolites and amino acids. Amino acids were analyzed by liquid chromatography coupled to either ultraviolet detection [16] or mass spectrometry [20]. Lipid and hexose (90-95\% glucose) analyses were performed by flow injection mass spectrometry using a Biocrates AbsoluteIDQ p150 kit (Biocrates Life Sciences AG, Innsbruck, Austria), which has been utilized previously for targeted metabolomics studies in children [11, 12]. The following lipid groups (number of metabolites) were determined: acylcarnitines (41), phosphatidylcholines (76), lysophosphatidylcholines (15), sphingomyelins (14, including 5 hydroxy-sphingomyelins), and 21 amino acids.

\section{Outcome Definition}

Weight change was defined as the difference between the weight at age 6 months and the birth weight. Weight measurements were transformed to age- and sex-specific WHO growth standards before subtraction to account for gender differences as well as deviations in the date of measurement and to allow interpretation of weight change differences as above or below the 'ideal' weight gain. As values of these WHO weight standards are designed to indicate the ideal weight at a specific age for the respective gender [18], a positive value for the differences of these standardized weight measurements indicates a higher-than-ideal velocity of weight gain (rapid growth), and a value below 0 for such a weight change slope could be interpreted as a less-than-ideal weight gain. Overweight or obesity at age 6 years is used as a distal outcome and is related to the metabolites are associated with infant weight change defined above. Overweight or obesity was defined as a body mass index (BMI) percentile of 90 or above and was derived from weight and height transformations according to WHO growth references for school-aged children and adolescents [21]. Note that a WHO-transformed BMI-SDS $>1.28$ is equivalent to the 90th percentile or above and was used as the cutoff point for the indicator-coded variable (1 vs. 0 ).

\section{Statistical Analysis}

A mainly explorative analysis approach with several steps was applied. In step 1, standard bivariate regression was applied to regress the WHO-standardized weight change outcome on each of the 168 measured metabolites. Each metabolite was 


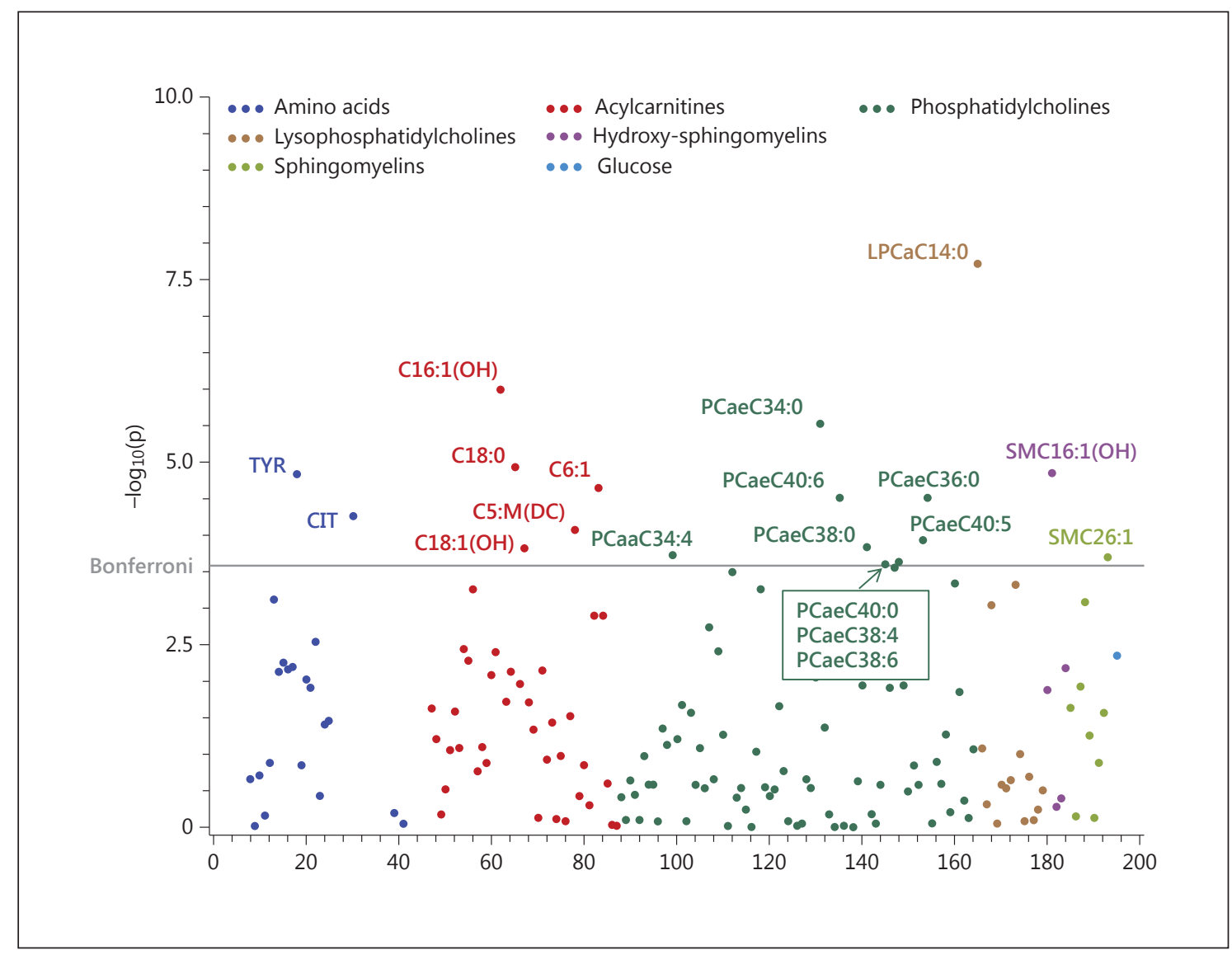

Fig. 1. Metabolites and weight change in the first 6 months of life (Manhattan plot, crude model). Note: metabolites were transformed to a standard normal distribution $(\mathrm{X} \sim \mathrm{N}[0 ; 1])$. Weights at birth and at age 6 months were standardized to WHO growth standards before calculation of weight change. Weight change is the outcome regressed on each metabolite separately without any adjustment. Cx:y represents an acyl group with chain length $\mathrm{x}$ and $\mathrm{y}$ double bonds. PCaa $=$ Diacyl-phosphatidylcholine; PCae $=$ acylakyl-phosphatidylcholine; LPCa = lysophosphatidylcholine with an acyl chain; TYR = tyrosine; CIT = citrulline. transformed to a standard normal distribution with a mean of 0 and a variance of 1 to account for the different measurement scale ranges and thus ease the evaluation of the effect sizes. In step 2, weight change-related metabolites were identified by Bonferroni-corrected pvalues [threshold $3.53=-\log _{10}(0.05 / 168)$ ] and illustrated using a Manhattan plot. The effect sizes, corrected $p$ values on the $-\log _{10}(p)$ scale, and explained variances of weight change for these significant metabolites are listed in table 2 . In step 3, the potential associations of significant metabolites with the outcome of BMI-SDS-defined overweight or obesity at age 6 years were explored by standard logistic regression.

All analyses were repeated with adjustment for feeding group (i.e. including the 2 indicator-coded variables low-protein feeding group and high-protein feeding group with the implicit reference group breast-fed) in analysis steps 1 and 2 to account for potential differences due to the study design. All statistical analyses were conducted using the software SAS 9.3 [22].

Metabolites, Early Rapid Growth, and Childhood Obesity

\section{Results}

The characteristics of the analyzed population are listed in table 1. No substantial differences were observed for offspring's birth weight, birth length, or gestational age among the randomized groups of low- or high-protein formula, and there were no statistical differences in the mother's birth weight, maternal or paternal prepregnancy BMI or maternal smoking during pregnancy, parental educational level, or the relative composition of the study population by study center among these feeding groups.

The father's birth weight was lower for the low-protein formula group compared to the group fed the high-protein formula. However, we do not consider this difference to be so substantial that the randomization of the formula-fed groups has to be questioned, and we do not con- 


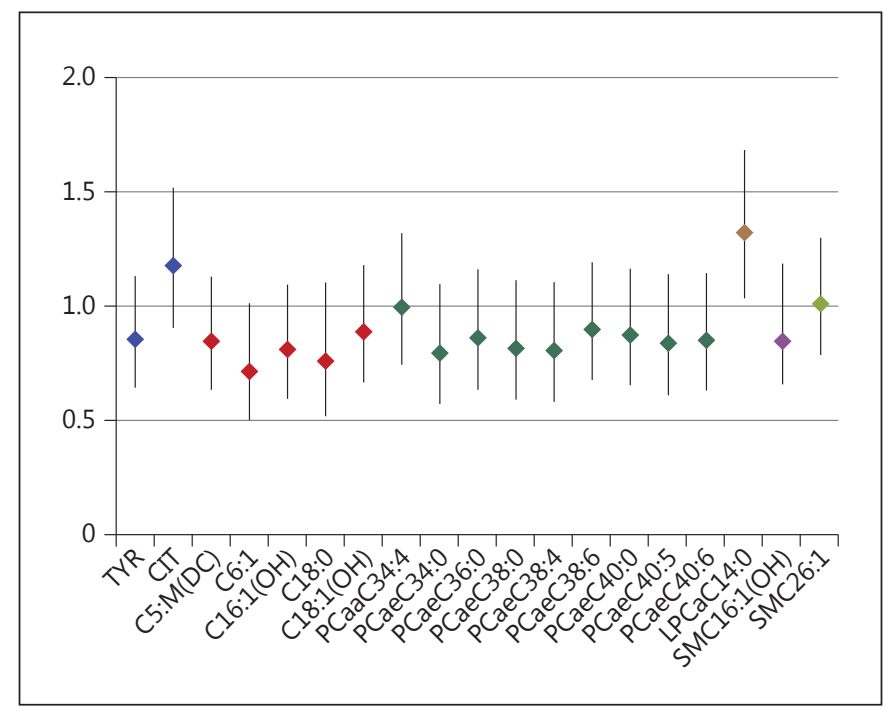

Fig. 2. Association of significant metabolites and overweight/obesity at age 6 years (OR with 95\% CI estimated by logistic regression, crude model). Cx:y represents an acyl group with chain length $x$ and $y$ double bonds. PCaa $=$ Diacyl-phosphatidylcholine; PCae $=$ acyl-akyl-phosphatidylcholine; LPCa = lysophosphatidylcholine with an acyl chain; TYR = tyrosine; CIT $=$ citrulline .

sider the differences in most of these characteristics among the breast-fed group and the formula-fed groups a problem regarding randomization as the breast-fed group was included only as an observational group in the $\mathrm{CHOP}$ cohort and consequently did not affect randomization. Nevertheless, associations of metabolites with weight change were also reported after adjustment for feeding group (see below) because there are clear differences in metabolite profiles among feeding groups in the CHOP study.

All $\mathrm{p}$ values of the 168 unadjusted regressions of the outcome WHO-standardized weight change in the first 6 months on each of the standard-normalized metabolites (see Materials and Methods) are depicted in a Manhattan plot style figure with all Bonferroni-corrected significant metabolites labeled (fig. 1). The size and direction of the effect, significance level, and explained variance are listed in table 2. The amino acids tyrosine and citrulline, the diacyl-phosphatidylcholine PCaaC34:4, and the lysophosphatidylcholine LPCaC14:0 were the only metabolites that resulted in a higher-than-ideal weight gain (rapid growth) during the first 6 months of life. All other 15 significant metabolites of the overall 19 significant ones showed a negative effect on the infants' weight change (lower-than-ideal weight gain). That is, 5 short- or long-
Table 2. Metabolites and weight change in the first 6 months of life Regression $-\log _{10}$ Explained coefficient (p) variance, $\%$

$\begin{array}{llll}\text { Amino acids } & & & \\ \text { TYR } & 0.16 & 4.8 & 2.6 \\ \text { CIT } & 0.15 & 4.3 & 2.2 \\ \text { Acylcarnitines } & & & \\ \text { C5:M(DC) } & -0.14 & 4.1 & 2.1 \\ \text { C6:1 } & -0.15 & 4.7 & 2.5 \\ \text { C16:1(OH) } & -0.18 & 6.0 & 3.3 \\ \text { C18:0 } & -0.16 & 4.9 & 2.6 \\ \text { C18:1(OH) } & -0.14 & 3.8 & 2.0\end{array}$

Phosphatidylcholines

Diacyl-phosphatidylcholines

PCaaC34:4
Acyl-akyl-phosphatidylcholines PCaeC34:0

$\begin{array}{lll}0.14 & 3.7 \quad 1.9\end{array}$

PCaeC36:0

$\begin{array}{lll}-0.17 & 5.5 & 3.0\end{array}$

PCaeC38:0

$-0.15$

PCaeC38:4

$-0.14$

PCaeC38:6

$-0.13$

$-0.13$

PCaeC40:0

$-0.13$

PCaeC40:5

$-0.14$

PCaeC40:6

$-0.15$

4.5

2.0

Lysophosphatidylcholines LPCaC14:0

$\begin{array}{lll}0.20 & 7.7 \quad 4.3\end{array}$

Hydroxy-sphingomyelins SMC16:1(OH)

$\begin{array}{lll}-0.16 & 4.9 \quad 2.6\end{array}$

Sphingomyelins SMC26:1

$-0.13$

3.7

1.9

Only metabolites significantly related to weight change resulting from unadjusted linear regression are listed. Cx:y represents an acyl group with chain length $\mathrm{x}$ and $\mathrm{y}$ double bonds. $\mathrm{PCaa}=$ diacyl-phosphatidylcholine; PCae = acyl-akyl-phosphatidylcholine; LPCa = lysophosphatidylcholine with an acyl chain; TYR = tyrosine; CIT $=$ citrulline.

chain acylcarnitines [C5:M(DC), C6:1, C16:1(OH), C18:0, and C18:1(OH)], 8 acyl-alkyl-phosphatidylcholines (PCaeC34:0, PCaeC36:0, PCaeC38:0, PCaeC38:4, PCaeC38:6, PCaeC40:0, PCaeC40:5, and PCaeC40:6), 1 hydroxy-sphingomyelin [SMC16:1(OH)], and 1 sphingomyelin (SMC26:1) were inversely related to weight change, indicating a somewhat flatter-than-ideal growth trajectory in the first 6 months of life.

It is interesting to note that the lysophosphatidylcholine LPCaC14:0, with $4.3 \%$, explained by far the most variance of infant weight change, followed by the acylcarnitine $\mathrm{C} 16: 1(\mathrm{OH})$ with $3.3 \%$ and the acyl-alkyl-phosphatidylcholine PCaeC34:0 with 3\%. However, only 
Table 3. Metabolites, weight change, and overweight/obesity after adjustment for feeding group

\begin{tabular}{|c|c|c|c|c|c|}
\hline & $\begin{array}{l}\text { Regression } \\
\text { coefficient }\end{array}$ & $\begin{array}{l}-\log _{10} \\
\text { (p) }\end{array}$ & $\begin{array}{l}\text { Explained } \\
\text { variance, \% }\end{array}$ & OR & $95 \% \mathrm{CI}$ \\
\hline \multicolumn{6}{|c|}{ Diacyl-phosphatidylcholines } \\
\hline PCaaC38:3 & 0.14 & 5.5 & 6.7 & 1.00 & $0.96-1.04$ \\
\hline \multicolumn{6}{|c|}{ Lysophosphatidylcholines } \\
\hline LPCaC14:0 & 0.18 & 7.7 & 7.8 & 1.33 & $1.04-1.69$ \\
\hline
\end{tabular}

LPCaC14:0 was significantly and strongly positively associated with overweight or obesity at age 6 years in these crude analyses (fig. 2). For higher levels of the acylcarnitine C6:1, the odds of overweight or obesity were substantially reduced, but this association just failed to be significant. All other weight change-related metabolites were clearly not associated with overweight or obesity at the age of 6 years (fig. 2).

Repeating these regressions with adjustment for feeding group to account for known differences in metabolite levels among the feeding groups in this study resulted in only 2 metabolites with a significant effect on infant weight change: the diacyl-phosphatidylcholine PCaaC38:3 and the lysophosphatidylcholine LPCaC14:0 (table 3 ). Both metabolites are positively associated with a higher-than-ideal weight gain (rapid growth) and explain a substantial part of the weight gain variance (about 6.7 and $7.8 \%$, respectively). It is interesting to note that $\mathrm{LPCaC} 14: 0$ had a significant positive relation with the highest effect size already in the crude analyses, whereas PCaaC38:3, though it showed a positive effect size $(\beta=0.10)$, was not significant even without adjustment for feeding group after Bonferroni's correction for multiple testing. Moreover, $\mathrm{LPCaC} 14: 0$ is the only metabolite that resulted in a significant and substantial association with overweight or obesity at age 6 years after adjustment.

\section{Discussion}

Exploration of the relationship of 168 metabolites of amino acid and lipid metabolism and weight change from birth up to age 6 months in this large prospective unselected cohort for 726 children revealed that 19 metabolites showed significant effects on infant weight change. Remarkably, only the amino acids tyrosine and citrulline, the diacyl-phosphatidylcholine PCaaC34:4,

Metabolites, Early Rapid Growth, and Childhood Obesity and the lysophosphatidylcholine LPCaC14:0 were related to higher-than-ideal weight gain (rapid growth) during the first 6 months of life. All other 15 significant metabolites, i.e. 5 short- or long-chain acylcarnitines [C5:M(DC), C6:1, C16:1(OH), C18:0, and C18:1(OH)], 8 acyl-alkyl-phosphatidylcholines (PCaeC34:0, PCaeC36:0, PCaeC38:0, PCaeC38:4, PCaeC38:6, PCaeC40:0, PCaeC40:5, and PCaeC40:6), 1 hydroxysphingomyelin [SMC16:1(OH)], and 1 sphingomyelin (SMC26:1) were associated with a lower-than-ideal weight gain in this 6-month period after correcting for multiple testing.

Our finding of a positive relation of tyrosine with rapid growth is in line with the results of one of the few longitudinal studies on metabolic profiles in youth which showed elevated levels of tyrosine after a quick weight recovery for adolescent anorexia patients [9]. A small study in healthy prepubertal and pubertal children with a focus on analysis of fasting circulating concentrations of branched-chain amino acids and potential insulin resistance 18 months after enrolment gave further, though indirect, plausibility to our finding by showing a positive correlation with fasting BMI-SDS and a greater effect on future HOMA insulin resistance not far from significance [23]. However, in contrast to our study, citrulline was negatively related to both BMI-SDS and future HOMA insulin resistance in that and another study in youth $[10,23]$. Rapid weight gain was also associated with levels of PCaaC34:4 in a longitudinal study in adolescent anorexia patients [9]. We could not identify further studies showing this effect either in youth or in younger children. However, this may be due to the lack of comprehensive metabolomics studies in children.

Our findings of a negative relation with rapid weight gain for some short- and long-chain acylcarnitines were only partly in line with those of the longitudinal study in anorexia patients [9]. The same is true regarding our results on short-chain acylcarnitines. However, in a crosssectional study, a negative relation of C5 and C6 acylcarnitines with BMI in normal-weight, obese, and type 3 diabetes youth was shown [10]. Our results regarding a negative relation of rapid weight gain and levels of acylakyl-phosphatidylcholines are also mixed. Only for PCaeC36:0, PCaeC38:6, PCaeC40:5, and PCaeC40:6 were these previous results in line with our findings. A negative relation to rapid weight gain as in our study was found for the sphingomyelin SMC26:1, but not for the hydroxy-sphingomyelin SMC16:1(OH) [9]. After accounting for feeding group (high- or low-protein formula or fully breast-fed), only LPCaC14:0 and 
PCaaC38:3 were positively associated with weight change (rapid growth). Interestingly, the latter was not significantly associated with weight change in the crude analyses. In addition to the relation with infant weight change up to the age of 6 months, LPCaC14:0 was the only metabolite which was also strongly and significantly associated (OR 1.33; 95\% CI 1.04-1.69) with overweight or obesity in infants at the age of 6 years. This may suggest that LPCaC14:0 may be a metabolic marker programmed by rapid weight gain. Furthermore, the metabolic alterations themselves may underpin further weight gain and later obesity. However, disentanglement of this causal conundrum with more certainty would require the availability of more longitudinal metabolic marker measurements over time. LPCaC14:0 is endogenously synthesized from phospholipase A2 by cleaving a fatty acid from the sn-2 position of the glycerol backbone of a diacyl-phosphatidylcholine containing the myristic acid C14:0 at the sn-1 position. Lysophosphatidylcholines and the resulting nonesterified fatty acid are the suggested form of transport into cells [24]. For example, lysophosphatdylcholine is proposed as the primary metabolite facilitating blood docosahexaenoic acid incorporation into the brain [25].

Despite the known importance of the first 6 months of life for metabolic programming of weight change [3, 4], we did not find any previously published metabolomics- or otherwise focused studies identifying a relationship of LPCaC14:0 with any kind of weight gain in the age group of interest, i.e. 6-month-old infants. Moreover, we did not find respective publications in any age group. Therefore, we cannot directly evaluate our finding regarding $\mathrm{LPCaC} 14: 0$ and more-than-ideal weight gain (rapid growth) in the context of previous publications. Consequently, replication of our finding in another independent cohort is definitely required. Other lysophosphatidylcholines have been related to weight loss (LPCaC18:1, LPCaC18:2, and LPCaC20:4) [12] or weight regain (LPCaC16:0, LPCaC16:1, LPCaC17:0, LPCaC18:0, LPCaC18:1, LPCaC18:2, LPCaC20:3, and LPCaC20:4) [9] in small longitudinal studies of children aged 11 or 15 years, respectively. However, both findings resulted from either obesity or anorexia treatment studies and were additionally based on special interventions in special populations. We did not find publications for our other main finding that higher LPCaC14:0 levels are associated with overweight or obesity in children at age 6 years, either.

Since molecular studies of different LPCa species like LPCaC14:0 are missing, it is difficult to provide a suit- able explanation for the effect of LPCaC14:0. LPCa are degraded to lysophosphatidic acids (LPA) [26], which are elevated in obese mice [27] and influence adipose tissue differentiation [28]. To our knowledge, no studies are available investigating the different effects of LPA on obesity development. It has only been stated that different LPA species have different biological activities on LPA receptors [29]. Thus, we can only raise the question of whether LPCaC14:0 or LPAaC14:0 has an adverse effect on human weight gain compared to other LPC or LPA species, but more in vitro, in vivo, or tracer studies are needed. However, analysis of the total plasma fatty acid composition in 59 obese children aged 12 years from a Japanese obesity clinic and 53 age- and sexmatched normal-weight children revealed that C14:0 the main fatty acid component of LPCaC14:0 - was elevated in obese adolescents [30]. Thus, our findings are indirectly in line with these results. An explicit association of elevated LPCaC14:0 levels with overweight or obesity was found only in a South Korean case-control study of 60 adult men [31]. Thus, we may speculate, as mentioned above, that elevated levels of LPCaC14:0 early in life may be a weight change-programmed metabolic marker for later obesity. However, more measurements over time for this and pathway-related metabolites would be required to give further evidence for such an interpretation.

Comparable to studies in children, most of the evidence for the role of LPCaC14:0 in obesity in adults has been obtained only via indirect analysis of total or free fatty acids. These studies have consistently shown elevated levels of C14:0 (myristic acid) in adults as well [13, 32,33 . A study on lean, healthy, metabolically healthy, and metabolically unhealthy obese adults showed that C14:0 even has a dose-response relationship with the status of obesity and according to the degree of obesityrelated inflammation [33]. Whether this would show up also in children with different degrees of obesity or explicitly for LPCaC14:0 is an open question. There is also evidence that myristic acid (C14:0) influences the size of fat cells [32] and augments insulin release [34]. Although most of the reported results on the role of LPCaC14:0 regarding weight gain or obesity are only indirectly based on fatty acid analysis (C14:0) or adult studies, its role as a programmed marker seems not to be implausible despite the gaps in the literature. The lack of further significant correlating phosphatidylcholines containing myristic acid indicates that there is no enhanced bioavailability of myristic acid. In the case of enhanced phospholipase activity, further lysophosphati- 
dylcholines should have shown a relation to weight change as well. Thus, it seems that a specific relation between LPCaC14:0 and a possible signaling pathway might be assumed.

\section{Strength and Limitations}

This is, to the best of our knowledge, the first study in an unselected and large cohort to examine the metabolic profile of weight change in the potentially developmentally decisive first 6 months of life and relate it to overweight or obesity in later childhood as well. Our exploratory findings of the role of $\mathrm{LPCaC} 14: 0$ in weight gain and obesity document the usefulness of such a targeted metabolomics approach, in particular for pediatrics and obesity research [7]. If replicated in an independent cohort, elevated LPCaC14:0 levels may prove to be an early and weight change-programmed metabolic marker for later obesity. Thus, this mainly exploratory and easy-to-apply approach may be used as a first step in the identification of interesting metabolites before complex pathway and functional network analyses are performed - similar to what is done using the GWAS approach $[35,36]$.

A potential limitation is that we did not have a baseline metabolic profile at birth, which could have allowed longitudinal analysis of both weight change and metabolic change to reduce the potential causal conundrum of whether rapid weight gain affected the metabolic profile at age 6 months or whether the metabolic profile at birth or its change in the first 6 months resulted in the observed rapid weight change. Although we consider analysis of the association of each metabolite one by one to be a good start, accounting for metabolic pathways and appropriate construction of metabotypes may be a useful and even necessary extension in a second, more thorough and targeted step of analysis [35-37].

\section{Conclusions}

The lysophosphatidylcholine LPCaC14:0 is consistently and strongly related to both rapid weight gain during the first 6 months of life and overweight/obesity at age 6 years. This suggests that rapid weight gain early in life may not only be associated with altered LPCaC14:0 levels but may also represent a metabolically programmed effect of weight gain on the later obesity risk. However, these results require confirmation by independent cohorts and with longitudinal metabolic marker data in addition to the longitudinal anthropo- metric data at hand. Moreover, a more detailed analysis of metabolic pathways and networks would be the next step and would strengthen these results further.

\section{Acknowledgements}

The work reported herein was carried out with partial financial support from the Commission of the European Communities, the 7th Framework Programme, contract FP7-289346-EARLY NUTRITION, and European Research Council Advanced Grant ERC2012-AdG - No. 322605 META-GROWTH. This paper does not necessarily reflect the views of the Commission and in no way anticipates the future policy in this area.

\section{European Childhood Obesity Trial Study Group}

Philippe Goyens, Clotilde Carlier, Joana Hoyos, Pascale Poncelet, and Elena Dain (Université Libre de Bruxelles, Brussels, Belgium); Noel Van Hees, Lieoise Martin, Annick Xhonneux, and Jean-Paul Langhendries (CHC St. Vincent, Jeange-Rocourt, Belgium); Ricardo Closa-Monasterolo, Joaquin Escribano, Veronica Luque, Georgina Mendez, Natalia Ferre, and Marta Zaragoza-Jordana (Institut d'Investigació Sanitaria Pere Virgili, Universitat Rovira i Virgili, Taragona, Spain); Marcello Giovannini, Enrica Riva, Carlo Agostoni, Silvia Scaglioni, Elvira Verduci, Fiammetta Vecchi, and Alice Re Dionigi (University of Milan, Milan, Italy); Jerzy Socha and Piotr Socha (Department of Gastroenterology, Hepatology and Immunology, Children's Memorial Health Institute, Warsaw, Poland); Anna Dobrzanska and Dariusz Gruszfeld (Neonatal Intensive Care Unit, Children's Memorial Health Institute, Warsaw, Poland); Anna Stolarczyk and Agnieszka Kowalik (Department of Pediatrics, Children's Memorial Health Institute, Warsaw, Poland); Roman Janas and Ewa Pietraszek (Diagnostic Laboratory, Children's Memorial Health Institute, Warsaw, Poland); Emmanuel Perrin (Danone Research Centre for Specialized Nutrition, Schiphol, The Netherlands); Rudiger von Kries (Division of Pediatric Epidemiology, Institute of Social Pediatrics and Adolescent Medicine, Ludwig Maximilians University of Munich, Munich, Germany); Helfried Groebe, Anna Reith, and Renate Hofmann (Klinikum Nürnberg Süd, Nürnberg, Germany), and Berthold Koletzko, Veit Grote, MartinaWeber, Peter Rzehak, Sonia Schiess, Jeannette Beyer, Michaela Fritsch, Uschi Handel, Ingrid Pawellek, Sabine VerwiedJorky, Iris Hannibal, Hans Demmelmair, Gudrun Haile, and Melissa Theurich (Division of Nutritional Medicine and Metabolism, Dr. von Hauner's Children's Hospital, University of Munich Medical Center, Munich, Germany).

\section{Disclosure Statement}

The authors declare no conflicts of interest. 


\section{References}

$>1$ Ong KK, Ahmed ML, Emmett PM, Preece MA, Dunger DB: Association between postnatal catch-up growth and obesity in childhood: prospective cohort study. BMJ 2000; 320:967-971.

-2 Druet C, Stettler N, Sharp S, Simmons RK, Cooper C, Davey Smith G, Ekelund U, LévyMarchal C, Jarvelin M-R, Kuh D, Ong KK: Prediction of childhood obesity by infancy weight gain: an individual-level meta-analysis. Paediatr Perinat Epidemiol 2012;26:1926.

3 Koletzko B, Brands B, Poston L, Godfrey K, Demmelmair H; EarlyNutrition Project: Early nutrition programming of long-term health. Proc Nutr Soc 2012;71:371-378.

4 Young BE, Johnson SL, Krebs NF: Biological determinants linking infant weight gain and child obesity: current knowledge and future directions. Adv Nutr 2012;3:675-686.

$>5$ Adams SH: Emerging perspectives on essential amino acid metabolism in obesity and the insulin-resistant state. Adv Nutr 2011;2:445456.

6 Zhang A, Sun H, Wang X: Power of metabolomics in biomarker discovery and mining mechanisms of obesity. Obes Rev 2013;14: 344-349.

$>7$ Mussap M, Antonucci R, Noto A, Fanos V: The role of metabolomics in neonatal and pediatric laboratory medicine. Clin Chim Acta 2013;426:127-138.

$>8$ Fanos V, Antonucci R, Atzori L: Metabolomics in the developing infant. Curr Opin Pediatr 2013, E-pub ahead of print.

>9 Föcker M, Timmesfeld N, Scherag S, Knoll N, Singmann P, Wang-Sattler R, Bühren K, Schwarte R, Egberts K, Fleischhaker C, Adamski J, Illig T, Suhre K, Albayrak Ö, Hinney A, Herpertz-Dahlmann B, Hebebrand J: Comparison of metabolic profiles of acutely ill and short-term weight recovered patients with anorexia nervosa reveals alterations of 33 out of 163 metabolites. J Psychiatr Res 2012; 46:1600-1609.

10 Mihalik SJ, Michaliszyn SF, de las Heras J, Bacha F, Lee S, Chace DH, DeJesus VR, Vockley J, Arslanian SA: Metabolomic profiling of fatty acid and amino acid metabolism in youth with obesity and type 2 diabetes: evidence for enhanced mitochondrial oxidation. Diabetes Care 2012;35:605-611.

-11 Wahl S, Yu Z, Kleber M, Singmann P, Holzapfel C, He Y, Mittelstrass K, Polonikov A, Prehn C, Romisch-Margl W, Adamski J, Suhre K, Grallert H, Illig T, Wang-Sattler R, Reinehr T: Childhood obesity is associated with changes in the serum metabolite profile. Obes Facts 2012;5:660-670.

-12 Reinehr T, Wolters B, Knop C, Lass N, Hellmuth C, Harder U, Peissner W, Wahl S, Grallert H, Adamski J, Illig T, Prehn C, Yu Z, Wang-Sattler R, Koletzko B: Changes in the serum metabolite profile in obese children with weight loss. Eur J Nutr 2014:1-9.
13 Newgard CB, An J, Bain JR, Muehlbauer MJ, Stevens RD, Lien LF, Haqq AM, Shah SH, Arlotto M, Slentz CA, Rochon J, Gallup D, Ilkayeva O, Wenner BR, Yancy WS Jr, Eisenson H, Musante G, Surwit RS, Millington DS, Butler MD, Svetkey LP: A branched-chain amino acid-related metabolic signature that differentiates obese and lean humans and contributes to insulin resistance. Cell Metab 2009;9: 311-326.

14 Koletzko B, von Kries R, Closa R, Escribano J, Scaglioni S, Giovannini M, Beyer J, Demmelmair H, Gruszfeld D, Dobrzanska A, Sengier A, Langhendries JP, Rolland Cachera MF, Grote V; European Childhood Obesity Trial Study Group: Lower protein in infant formula is associated with lower weight up to age 2 y: a randomized clinical trial. Am J Clin Nutr 2009;89:1836-1845.

15 Rzehak P, Grote V, Lattka E, Weber M, Gruszfeld D, Socha P, Closa-Monasterolo R, Escribano J, Giovannini M, Verduci E, Goyens P, Martin F, Langhendries JP, Demmelmair H, Klopp N, Illig T, Koletzko B; European Childhood Obesity Trial Study Group: Associations of IGF-1 gene variants and milk protein intake with IGF-I concentrations in infants at age 6 months - results from a randomized clinical trial. Growth Horm IGF Res 2013;23:149-158.

16 Socha P, Grote V, Gruszfeld D, Janas R, Demmelmair H, Closa-Monasterolo R, Escribano Subías J, Scaglioni S, Verduci E, Dain E, Langhendries J-P, Perrin E, Koletzko B; European Childhood Obesity Trial Study Group: Milk protein intake, the metabolic-endocrine response, and growth in infancy: data from a randomized clinical trial. Am J Clin Nutr 2011;94:1776S-1784S.

17 Weber M, Grote V, Closa-Monasterolo R, Escribano J, Langhendries JP, Dain E, Giovannini M, Verduci E, Gruszfeld D, Socha P, Koletzko B; European Childhood Obesity Trial Study Group: Lower protein content in infant formula reduces BMI and obesity risk at school age: follow-up of a randomized trial. Am J Clin Nutr 2014;99:1041-1051.

18 de Onis M, Onyango A, Borghi E, Siyam A, Blossner M, Lutter C; WHO Multicenter Growth Reference Study Group: Worldwide implementation of the WHO child growth standards. Public Health Nutr 2012;15:16031610.

19 Schulz KF, Altman DG, Moher D; CONSORT Group: Consort 2010 statement: updated guidelines for reporting parallel group randomised trials. J Clin Epidemiol 2010;63:834840 .

20 Harder U, Koletzko B, Peissner W: Quantification of 22 plasma amino acids combining derivatization and ion-pair LC-MS/MS. J Chromatogr B Analyt Technol Biomed Life Sci 2011;879:495-504.
21 de Onis M, Onyango AW, Borghi E, Siyam A, Nishida C, Siekmann J: Development of a who growth reference for school-aged children and adolescents. Bull World Health Organ 2007;85:660-667.

22 SAS Institute Inc.: SAS/STAT 9.2 User's Guide, ed 2. Cary SAS Institue Inc., 2009.

23 McCormack SE, Shaham O, McCarthy MA, Deik AA, Wang TJ, Gerszten RE, Clish CB, Mootha VK, Grinspoon SK, Fleischman A: Circulating branched-chain amino acid concentrations are associated with obesity and future insulin resistance in children and adolescents. Pediatr Obes 2013;8:52-61.

24 Lemaitre-Delaunay D, Pachiaudi C, Laville M, Pousin J, Armstrong M, Lagarde M: Blood compartmental metabolism of docosahexaenoic acid (DHA) in humans after ingestion of a single dose of [(13)C]DHA in phosphatidylcholine. J Lipid Res 1999;40:1867-1874.

25 Picq M, Chen P, Perez M, Michaud M, Vericel E, Guichardant M, Lagarde M: DHA metabolism: targeting the brain and lipoxygenation. Mol Neurobiol 2010;42:48-51.

26 Rancoule C, Dusaulcy R, Treguer K, Gres S, Guigne C, Quilliot D, Valet P, SaulnierBlache JS: Depot-specific regulation of autotaxin with obesity in human adipose tissue. J Physiol Biochem 2012;68:635-644.

27 Rancoule C, Dusaulcy R, Treguer K, Gres S, Attane C, Saulnier-Blache JS: Involvement of autotaxin/lysophosphatidic acid signaling in obesity and impaired glucose homeostasis. Biochimie 2014;96:140-143.

28 Yung YC, Stoddard NC, Chun J: LPA receptor signaling: pharmacology, physiology, and pathophysiology. J Lipid Res 2014, E-pub ahead of print.

29 Aoki J, Inoue A, Okudaira S: Two pathways for lysophosphatidic acid production. Biochim Biophys Acta 2008;1781:513-518.

30 Okada T, Furuhashi N, Kuromori Y, Miyashita M, Iwata F, Harada K: Plasma palmitoleic acid content and obesity in children. Am J Clin Nutr 2005;82:747-750.

31 Kim JY, Park JY, Kim OY, Ham BM, Kim HJ, Kwon DY, Jang Y, Lee JH: Metabolic profiling of plasma in overweight/obese and lean men using ultra performance liquid chromatography and Q-TOF mass spectrometry (UPLCQ-TOF MS). J Proteome Res 2010;9:43684375.

32 Garaulet M, Hernandez-Morante JJ, Lujan J, Tebar FJ, Zamora S: Relationship between fat cell size and number and fatty acid composition in adipose tissue from different fat depots in overweight/obese humans. Int J Obes (Lond) 2006;30:899-905.

33 Perreault M, Zulyniak MA, Badoud F, Stephenson S, Badawi A, Buchholz A, Mutch DM: A distinct fatty acid profile underlies the reduced inflammatory state of metabolically healthy obese individuals. PLoS One 2014; 9:e88539. 
34 Komatsu M, Sharp GW: Palmitate and myristate selectively mimic the effect of glucose in augmenting insulin release in the absence of extracellular $\mathrm{Ca}^{2+}$. Diabetes 1998;47:352357.

35 Demirkan A, van Duijn CM, Ugocsai P, Isaacs A, Pramstaller PP, Liebisch G, Wilson JF, Johansson Å, Rudan I, Aulchenko YS, Kirichenko AV, Janssens ACJW, Jansen RC, Gnewuch C, Domingues FS, Pattaro C, Wild SH, Jonasson I, Polasek O, Zorkoltseva IV, Hofman A, Karssen LC, Struchalin M, Floyd J, Igl W, Biloglav Z, Broer L, Pfeufer A, Pichler
I, Campbell S, Zaboli G, Kolcic I, Rivadeneira F, Huffman J, Hastie ND, Uitterlinden A, Franke L, Franklin CS, Vitart V, Nelson CP, Preuss M, Bis JC, O’Donnell CJ, Franceschini N, Witteman JCM, Axenovich T, Oostra BA, Meitinger T, Hicks AA, Hayward C, Wright AF, Gyllensten U, Campbell H, Schmitz G, et al; DIAGRAM Consortium; CARDIoGRAM Consortium; CHARGE Consortium; EUROSPAN Consortium: Genome-wide association study identifies novel loci associated with circulating phospho- and sphingolipid concentrations. PLoS Genet 2012;8:e1002490.
6 Krumsiek J, Suhre K, Illig T, Adamski J, Theis FJ: Gaussian graphical modeling reconstructs pathway reactions from high-throughput metabolomics data. BMC Syst Biol 2011;5:21.

37 Petersen AK, Zeilinger S, Kastenmuller G, Romisch-Margl W, Brugger M, Peters A, Meisinger C, Strauch K, Hengstenberg C, Pagel P, Huber F, Mohney RP, Grallert H, Illig T, Adamski J, Waldenberger M, Gieger C, Suhre K: Epigenetics meets metabolomics: an epigenome-wide association study with blood serum metabolic traits. Hum Mol Genet 2014; 23:534-545. 